Вестник Новосибирского государственного педагогического университета

(С) И. В. Брыллина

DOI: $10.15293 / 2226-3365.1805 .09$

УДК 316.74+378.015.2-0.43.86

ФОРМИРОВАНИЕ НОВОГО АНТРОПОЛОГИЧЕСКОГО ПРОЕКТА СОВРЕМЕННОГО ОБРАЗОВАНИЯ В КОНТЕКСТЕ НЕКЛАССИЧЕСКОЙ ФИЛОСОФИИ*

\author{
И. В. Брылина (Томск, Россия)
}

Проблема и цель. Исследуется проблема переоценки западноевропейского классического наследия философией образования. Цель исследования - выявить потенциал неклассической философии к формированию нового антропологического проекта современного образования.

Методология. В статье использованы методы анализа и синтеза при исследовании генезиса и эволюиии образования в разные исторические эпохи: от Античности до наших дней. Метод сравнительного анализа применен к сопоставлению и выявлению различий антропологических проектов классической и неклассической философии как способах связи человека и образования. Эксплииированы категории «заботы о себе» Платона и «техник себя» М. Фуко. На основе неклассической методологии (принициов системности, самоорганизации и саморазвития) выявлены тенденции и потенциал современного образования в формировании актуальных качеств обучаюшегося.

Результаты. Обоснована связь эволючии человека с трансформацией образования. Проанализирована смена антропологических проектов в контексте эволюиии образования от Античности до наших дней. Проведено сравнение античной практики «заботы о себе» Платона и «техник себя» М. Фуко.

Заключение. Сделан вывод, что новый антропологический проект отличается от классического проекта, в основание которого было положено «восхождение» кединой форме, идеалу, образиу, норме, смыслу, истине (Эйдос - Бог - Красота - Опьт - Рацио - Воля) тем, что в условиях изменчивости, неопределенности бытия отсутствует единый идеал, готовая форма, а основным антропологическим ориентиром современного образования становится стратегия самоорределения, саморазвития, самосозидания обучающегося.

Ключевые слова: эволючия человека; философия образования; эволючия образования; трансформация образования; новый антропологический проект; самоопределение; самосозидание.

\section{Постановка проблемы}

Последние десятилетия происходит

стремительное изменение социальной реаль- ности и самого человека. Подвергнутыми сомнению и пересмотру оказываются культурные основания общества, воспитание и образование человека.

*Исследование поддержано Томским политехническим университетом.

Брылина Ирина Владимировна - кандидат философских наук, доцент, Отделение социальногуманитарных наук Школы базовой инженерной подготовки, Национальный исследовательский Томский политехнический университет.

E-mail: ibrylina@yandex.ru 
Как изменилось современное образование в связи с глобализационными процессами, маркетизацией и консъюмеризацией общества, коммерциализацией образования, коммодификацией знания? Какой человек востребован в новых социокультурных условиях? Образ какого человека призвано формировать современное образование, чтобы в условиях «текучей» реальности (3. Бауман [1]), «сверхсложности» (Р. Барнетт [2]), «обществе риска» (У. Бек [3]), основные характеристики которых неуверенность, неопределенность, небезопасность, успешно действовать, развить свои адаптивные способности, снижать рискогенность социума?

Поиск ответов на эти вопросы актуализирует философское переосмысление антропологического проекта современного образования.

Постановка проблемы реформирования образования в XXI веке вызвана всем ходом эволюции человека и общества, и связана с кризисом всей системы мировой цивилизации и глобальными мировоззренческими сдвигами. Новая адаптация человека к этим изменениям актуализирует применение антропологического подхода к образованию ${ }^{1}$, переоценку философией образования [4] западноевропейского классического наследия, обращение к философским идеям М. Хайдеггера, М. Фуко [5-6] и др.

В то время как классический антропологический проект был направлен на формирование определенной (о-пределенной) личности, сообразующейся с готовым идеалом

\footnotetext{
${ }^{1}$ Goodman R. Education: Anthropological Aspects // International Encyclopedia of the Social \& Behavioral Sciences (Second Edition). - Elsevier, 2015. - P. 144-148. DOI: https://doi.org/10.1016/B978-0-08-097086-8.12060-4; Levinson B. A., Gonzalez N., Anderson-Levitt K. Anthropological Approaches to the Study of Education: The United States
}

своей эпохи, образ человека XXI века, формирующийся в современной зарубежной науке, основан на стратегии самоопределения личности [7-8] (CDT - Self-Determination Theory) Р. М. Райана и Э. Л. Деси [9-10], и получивший широкое распространение в исследованиях отечественных авторов [11].

Целью исследования является выявление потенциала неклассической философии к формированию нового антропологического проекта современного образования: поиск им новых стратегий, форм, методов идентичности обучающегося.

\section{Методология исследования}

В статье использованы методы анализа и синтеза при исследовании генезиса и эволюции образования в разные исторические эпохи: от Античности до наших дней. Метод сравнительного анализа применен к сопоставлению и выявлению различий антропологических проектов классической и неклассической философии как способах связи человека и образования. Эксплицированы категории «заботы о себе» Платона и «техник себя» М. Фуко. На основе неклассической методологии (принципов системности, самоорганизации и саморазвития) выявлены тенденции и потенциал образования в формировании актуальных качеств обучающегося.

\section{Результаты исследования}

Эволючия образования в контексте эволючии антропологических проектов. Эпохой Античности было предложено такое толкование образования, теоретическим основанием и

and Beyond // International Encyclopedia of the Social \& Behavioral Sciences (Second Edition). - Elsevier, 2015. P. 728-733. DOI: https://doi.org/10.1016/B978-0-08097086-8.92053-1 
предпосылкой которого являлось понимание того, чему предназначен человек - стать самим собой, следовать своей природной сути.

Платон в диалоге «Государство» ${ }^{2}$ раскрыл существо образования (раідеiа) как путь и процесс совершенствования добродетели посредством познания и через наставление в искусствах как изменение способа существования человека. В мире Платона через образование реализует себя воспоминание, возвращение к истине бытия. Самопознание - в узнавании своего образа, узнавание себя в границах высшего единства. Человек посредством самопознания открывается своей сути, оказывается обращенным к истине своего бытия, в этом смысле образование представляет собой онтологический акт. Одновременно через процесс образования совершается обращенность к тому, что имеет характер всеобщности - это образ-Эйдос. В образовании - осуществление общей идеи человека.

Средние века предлагают иную интерпретацию образования: это восстановление неискаженного греховностью образа Бога, это созерцание Бога и делание.

Антропологическая проблематика Peнессанса в понимании существа образования исходит из идеи творчески деятельной и активной личности, независимой в своих поступках и начинаниях. Возвращаясь к идеалам и ценностям Античности, эпоха Ренессанса толкует образование как формирование и культивирование данного Природой (понимание, воспринятое Новым временем), т. е. акцент делается на индивидуально-личностном, творчески-деятельностном начале человека.

В эпоху Просвещения порожден дискурс образования, базирующийся на принципе ра- циональной коммуникации. Образование, органично связанное с культурой, с этих пор стало обозначением специфического человеческого способа преобразования того, чем человека (ведомого) наделила природа: возможностей, задатков. И. Г. Гердер назвал этот процесс «возрастанием к гуманности», «воспитанием гуманности» ${ }^{3}$.

В немецкой классической философии формируется специфическая интерпретация. Так, И. Кант, хотя и не употребляет термин «образование», под образованием понимает «культуру способностей», «природных задатков», определяющих свободу действующего субъекта (в образовании формируется нравственность - это практическое воспитание, оно отличается от школьного обучения, формирующего умения, и прагматического воспитания, формирующего разумность). Стимулирование таланта - нравственная обязанность обучаемого, ведомого Волей.

Позднее Г.-В. Ф. Гегель это требование заключил в границы размышлений о самообразовании. Образование, включив понятие «образ», получает значение отображения, слепка, образца. Г.-В. Ф. Гегель, формируя понятие «образование», говорит о том, что субъект разрывает связь с природным необходимым. Субъекту нужно образование для восхождения ко всеобщему, субъект нуждается в этом восхождении. Это восхождение, включающее теоретическое и практическое образование, есть сущностное определение целостности человеческой разумности. В процессе образования человек превращается в духовное существо. Это существо способно на жертву общему особенным, оно способно обуздывать влечения, определяя тем самым свободу от

\footnotetext{
2 Платон. Государство. - М.: Академический проект, 2015. - $398 \mathrm{c}$.
}

\author{
${ }^{3}$ Гердер И. Г. Идеи к философии истории человече- \\ ства. - М.: Наука, 1977. - С. 131.
}


предметов влечений ради свободы своей предметности. Это примирение субъекта с собой: то примирение, что позволяет субъекту узнавать себя в инобытии. Уходя от природной сущности, погружаясь в пределы сферы духа, индивид в культуре своего народа находит то, чем стремится овладеть. При этом речь идет не об отчуждении, а о возвращении к себе, но через отчуждение: отчуждение при этом играет роль основания возвращения к себе. В процессе образования осуществляется восхождение духа в сферу всеобщего, эта стихия для образованного субъекта, позволяющая овладеть субстанцией, уйти от природной сущности всего, - последнее возможно лишь посредством обращения к абсолютному философскому знанию через Разум.

Таким образом, немецкая классическая философия интерпретирует образование, исходя из идеи всеобщего: это то следование прообразу, что задает человеку его рамки, становление человека - следование общему, пределом и целью образования выступает «всеобщее». Для человека процесс образования есть то, что Г.-В. Ф. Гегель называет сообразование с субстанцией: человек утверждает себя в качестве всеобщего, приближаясь к всеобщности. Приближаясь к всеобщности, человек постигает через это приближение возможность онтологического господства: «Будучи уверенным, что этот мир есть его субстанция, самосознание старается овладеть им. Оно достигает власти над миром благодаря образованности» ${ }^{4}$. Эта власть над миром ограничена сферой чистого мышления. И цель образования в чистом незаинтересованном знании.

Обобщая сказанное, можно увидеть, что западноевропейская классическая традиция в интерпретации сущности образования исходит из видения его непосредственной связи с природой и сущностью человека, однако видение этой сущности различается в разные исторические эпохи.

В античном антропологическом проекте сущность человека понимается как восхождение к Эйдосу, в средневековом - человек сообразует себя с Богом, возрожденческий - ассоциирует природу человека с его творчеством, которое является основным фактором самореализации, индивидуализации. Нововременной - осмысляет природу человека через поиск истины посредством опыта (Бэкон), разума (Декарт, Гегель), чувств (Локк, Гоббс) или воли (Кант). Можно сказать, что каждый философ и каждая эпоха формируют свой антропологический проект, однако, при всех видимых различиях можно видеть общность западноевропейской классической традиции, которая характеризуется видением антропологических проблем, понимающих природу и сущность человека как следование определенному готовому образцу, идеалу, истине.

Следовательно, можно говорить о едином антропологическом проекте западноевропейской философской традиции как классическом. Однако, анализируя эволюцию образования в XX-XXI веках, мы неизбежно должны ориентироваться на те изменения, которые произошли с обществом и человеком. В XX веке формируется неклассическая интерпретация человека, исходящая из иных предпосылок.

Г.-Г. Гадамер ${ }^{5}$ в решении вопроса о сути образования принимает во внимание предпосылки классического подхода к существу человека. Он, характеризуя образование как подлинно историческое понятие, писал, что

\footnotetext{
${ }^{4}$ Гегель Г. В. Ф. Система наук. Ч. 1. Феноменология духа. - СПб.: Наука, 1999. - С. 26.
${ }^{5}$ Гадамер Г.-Г. Истина и метод: Основы философской герменевтики. - М.: Прогресс, 1988. - 704 с.


именно об этом историческом характере «сохранения» нужно говорить и думать, пытаясь уяснить суть гуманитарных наук. Образование интерпретируется им как процесс и одновременно результат процесса приобретения социально-значимых умений, навыков, знаний. Кроме того, что это процесс создания образов-образцов (истины), необходимых для формирования механизмов сохранения и передачи того, что накоплено культурой, это и метод. В образовании проявляет себя открытость различным позициям, это выход за границы существующей ситуации. Для индивида, исторически обусловленного культурой и обращенного к сформированным традициям, образование - это базис, платформа, с помощью которой можно осуществить вхождение в коммуникационное пространство культуры. Для образованного человека мир предстает в качестве тотального текста, наполненного смыслом, образование - понимание себя перед текстом.

Два образа практики «заботы о себе». Многие исследователи считают, что для понимания различия антропологических проектов в классическом и неклассическом дискурсах большим эвристическим потенциалом обладает обращение к античной духовной практике «заботы о себе» ${ }^{6}$ [12-14].

Остановимся подробнее на анализе античной духовной практики «заботы о себе» на примере философии Платона. В диалоге «Протагор» он впервые заявляет о самой возможности передачи социально-значимой добродетели. Сократ у Платона мучим сомнением: сможет ли Протагор обучить юного Гиппо-

\footnotetext{
${ }^{6}$ «Забота о себе» как образовательная практика современного классического университета: сборник статей и материалов международной научной конференции / отв. ред. Г. И. Петрова. - Томск: Изд-во Том. ун-та, 2018. - $306 \mathrm{c}$.
}

крата. И вывод, получаемый в процессе дискуссии, для Сократа заключен в тезисе: для государства должно существовать единое добродетель, ей должны быть сопричастны все, и высшая добродетель - знание, этой добродетели гражданин обучаем.

М. Хайдеггер ${ }^{7}$ утверждает, что впервые суть образования раскрыта Платоном в «Государстве» в «Мифе о пещере» ${ }^{8}$, где вводится понятие «пайдейи». Глубоко символичным в «Мифе о пещере» является освобождение узника от оков, сдерживающих его в пещере. И, если в пещере перед ним лишь образы, тени вещей, предстающие в мерцающих отблесках огня, то выход из пещеры сопряжен для узника с обретением знания действительного. Смысл образования отражен посредством обращения к цепи образов: пещера символизирует повседневность, в которой человек пребывает, а огонь - небесный свод. Выход к свету - это символ того изменения, которое претерпевает душа, когда происходит развертывание заложенного в ней ранее. Это переучивание и приучение к отведенной душе области и есть то, что названо Платоном пайдейей: руководством к изменению человека в его существе, руководство определенным образом. «Миф о пещере» в заключительной части повествует о спуске узника в пещеру, это тоже символ: постоянное преодоление незнания есть сущностная составляющая образования. Узник устремлен к Солнцу: оно - образ идеи добра как высшей ценности. Восхождение к добродетели и забота о себе связаны: лишь заботясь о себе, человек может управлять другими. Забота о себе превращается в искусство. И здесь огромна значимость

\footnotetext{
${ }^{7}$ Хайдеггер М. Учение Платона об истине // Хайдеггер М. Время и бытие: Статьи и выступления: пер. с нем. - М.: Республика, 1993. - 447 с.

8 Платон. Государство. - М.: Академический проект, 2015. - 398 c.
} 
наставника. Он являет своей жизнью образец того, каким образом должен заботиться о себе направляемый. Завершение заботы о себе - в самопознании как высшей степени выражения «Я». Именно это высшее выражение своего «Я» осуществляет доступ к истине. Этот доступ к истине, её постижение позволяет увидеть и признать заключенное в себе божественное начало. Самореализация - то, к чему приводит «забота о себе», она осуществляется через ошибки и заблуждения. Основная идея самореализации - стать тем, кем человек ранее не был.

Помимо Платона, сходное осмысление практики «заботы о себе» обнаруживается в античной философии у Эпикура, Сенеки, Луцилия, Эпиктета, Марка Аврелия. «Забота о себе» связывается ими, прежде всего, со «службой душе», хотя можно встретить и иные - медицинские и аскетические практики «заботы о себе», связанные с телесностью.

В дискурсе неклассической философии осмысление практики «заботы о себе» представлено в философии М. Фуко. В работах третьего этапа, названного «эстетикой существования», М. Фуко пишет о формировании морального субъекта, используя конструкт «техники себя» ${ }^{9}$, направленный не столько на самопознание, исходящего из античного Дельфийского принципа, сколько на самоизменение.

Такой подход позволил ему увидеть субъекта «не в стационарной сущности, не в ограничивающих его пределах, но в подвижных и постоянных практиках субъективации,

\footnotetext{
${ }^{9}$ Фуко М. История сексуальности - III: Забота о себе. Киев: Дух и литера; Грунт; М.: Рефл-бук, 1998. - 288 с.

${ }^{10}$ Гусаковский М. А. Современный дискурс воспитания в университете: смена правил игры // «Забота о себе» как образовательная практика современного классического университета: сборник статей и материалов международной научной конференции / отв. ред. Г. И. Петрова. - Томск: Изд-во Том. ун-та, 2018. - С. 3-12.
}

которые прилагаются извне, но преломляются изнутри» ${ }^{10}$. Стратегии субъективации - «особые способы подчинения себя, когда формы господства общества над субъектом встречаются с его властью над самим собой, когда есть дисциплина, но также и самодисциплина, контроль, но и самоконтроль. Субъект - это эффект власти, властвующей над собой, эффект знания, обращенного на себя, морали, судящей собственную систему регулятивов. Вне этой диспозиции субъекта не существует» ${ }^{11}$.

М. Фуко сдвигает исследовательский акцент с человека познающего-познаваемого на человека, направленно формирующего свой физический и духовный облик, рефлексирующего над собой [15-17]. Он называет его «Человеком вожделеющим», дополняя аспект сознательно формируемой духовности человека его телесностью, самостью. Для самости как субъективности существенным в понятии «забота» является практический мотив. Согласно М. Фуко, именно изменение морали удовольствий сказалось на способе, посредством которого индивидуум полагает себя в качестве морального субъекта. Сексуальное удовольствие рассматривается им как сила, которую субъект должен преодолевать и подчинять своей власти. Идеи самоформирования субъекта как сексуальности и его отношений с миром людей и обязанностей раскрываются М. Фуко через обращение человеком на себя нормативных практик, которые позволяют ему себя дисциплинировать и индивидуализировать.

\footnotetext{
${ }^{11}$ Михель Д. В. Мишель Фуко в стратегиях субъективации: от «Истории безумия» до «Заботы о себе». Материалы лекционных курсов 1996-1998 годов: монография. - Саратов: Поволжский филиала Российского учебного центра, 1999. - 136 с.
} 
Наконец, критерием успеха такой работы выступает умение индивидуума властвовать над собой, выковывать личные «стили жизни».

Самореализация у М. Фуко всегда осуществляется посредством обращения к Другому. М. Фуко, обращаясь к идее добродетели у Платона, пишет о различных типах отношения к Другому у молодого человека: наставление примером, наставление знаниями, наставление в трудности (тип наставления, в основание которого положено мастерство выхода из трудной ситуации). Формируемый молодой человек обращен к наставнику, философу, и наставник играет роль исполнителя преобразования молодого человека в качестве субъекта.

В интерпретации М. Фуко можно видеть различие между педагогикой и психагогикой. Если педагогические усилия направлены на передачу истины, вооружающей субъекта отношениями, способностями, знаниями, - все это субъект получает по завершению образования, то психагогические усилия ориентированы на передачу истины, меняющей само существо способа бытия обучаемого ${ }^{12}$. М. Фуко отвергает педагогику, как направленность на формирование человека согласно какомулибо образцу. Фигуре наставника Античности составляет конкуренцию идея самореализации субъекта, которая выступает, вместе с тем, значимой социальной практикой.

Таким образом, можно видеть, что в дискурсе неклассической философии на примере философии М. Фуко происходит разрыв с классическим антропологическим проектом, согласно которому человек формируем извне, под готовый, заданный эпохой идеал, готовую истину. Неклассический антропологический

\footnotetext{
12 Фуко М. Герменевтика субъекта: курс лекций, прочитанных в Коллеж де Франс в 1981-1982 учебном году / пер. с фр. А. Г. Погоняйло. - СПб.: Наука, 2007. -677 c.
}

проект формируется в контексте экзистенциальной философии (С. Кьеркегора, Ф. Ницше, М. Хайдеггера и др.), когда мир рассматривается как абсурдный, бытие характеризуется неопределенностью, а субъект, не имея никакой определенной сущности, находится в ситуации поиска идентичности через самоопределение и самоформирование.

Новый антропологический проект современного образования. Как сказано выше, в $\mathrm{XX}$ веке философская традиция характеризуется трансформацией антропологических оснований и принципов. Эти принципы подвержены переосмыслению, как и понимание существа гуманизма. В пределах этой традиции сформировалась тенденция проблематичности бытия человека. С. Степанова, обращаясь к этой проблеме в работах С. Кьеркегора и Ф.- В. Ницше, справедливо утверждает, что человек был поставлен под вопрос, т. к. его сущность, не определенная изначально, полагаема в процессе самостановления. Предназначение человека - в возврате к онтологическому истоку, в обретении идентичности ${ }^{13}$. Такое толкование сути человека означало трансформацию толкования сути образования. Не менее важным является и то, что эта ситуация способствовала возрождению смыслов, заключенных в paideia, - образование интерпретируется в качестве категории бытия, а не знания и переживания.

Это то, о чем К. Ясперс в «Смысле и предназначении истории» пишет следующим образом: «Образ, задающий направленность образования, не дан как всеобщая сущность

\footnotetext{
13 Степанова С. Н. Трансформация «идеи университета» в эволюционирующем образовательном пространстве: автореф. дис. ... канд. филос. наук. Улан-Удэ, 2010. - 38 с.
} 
человека, но предполагает достижение самоидентичности через раскрытие уникальности и самобытности человека» ${ }^{14}$.

Характерная особенность университетского образования сегодня связывается с трансформацией антропологических оснований современной культуры. Авторы, анализирующие эту проблему [16; 21-23], отмечают трансформацию типа личности, ее гражданских характеристик, интеллектуального потенциала. «Классическое университетское образование, - пишет об этой ситуации Л. И. Ямпольская, - представляло собой воспроизводство всеобщего образа, реализуемого через просветительскую миссию “формообразования”, возведения человека к единой истине и единой культуре. В истории образования, на различных ее культурных этапах принцип восхождения/возведения при различных и социально-экономических, и политических режимах всегда оставался. В этом сказывалась установка философского стиля мышления, его задачи обобщения и представления мира в понятийной форме» [19, с. 95].

Идея образования заключалась в том, чтобы возвести к созданному ранее образу, приобщив обучаемого к этому образу. Такой антропологический проект создавался посредством единства образа и идеала. Г. Н. Петрова [16; 21] отмечает, что в основании подобного рода антропологического проекта положено представление о типе социального развития, который концептуализирован в пределах классического субстанциалистского стиля философского мышления. Культурное развитие в пределах данного типа социального развития осуществлялось в соответствии со строгой закономерностью, было однолинейно направлено, следовало традиции, опиралось на нормы и идеалы. Образование ориентировалось на идеал, этим идеалом было Просвещение.

В XX веке ситуация изменилась. Стиль научного мышления, тип организации социальности, как и тип социокультурного развития, был подвергнут натиску деконструктивизма. Был сформирован круг проблем, разрешить которые было можно, но лишь в проблемном горизонте неклассической традиции: «...Общая тенденция изменений в образовании, его антропологическом проекте - отказ от определяющего значения сущности как задаваемой извне нормы, по которой образованию надлежит работать. Культурфилософский деконструктивизм, совершенный относительно единой субстанции-сущности, предложил в новых формах концептуализировать и образование, и социальность в целом. Философское осмысление современного образования и его антропологический проект могут быть аутентичными лишь при условии исследования их в ракурсе трансформации, которую несет с собой коммуникативная онтология социальности и культуры» [21, с. 97].

Резонансом философского деконструктивизма стало то, что сформировались разнообразные концептуализации образования, а антропологический проект образования был серьезно модифицирован. Образование утратило свой «формообразовательный» смысл, так возникла необходимость в новом проекте образования, ориентированном на новый тип обучаемого.

Формирующийся философско-антропологический проект современного образования максимально адаптивен, междисциплинарен в своем предметном содержании.

Исследованию нового образа обучаемого в современной российской философской

\footnotetext{
${ }^{14}$ Ясперс К. Смысл и назначение истории: пер. с нем. М.: Политиздат, 1991. - С. 363. 
литературе уделено много внимания Г. И. Петровой $[16 ; 18 ; 21 ; 26]$, Л. Казариной [22], А. О. Карповым [23], Д. Н. Боровинской [20; 24] и др.

Какими видятся его сущностные характеристики?

По 3. Бауману, входным билетом в новую глобальную элиту является «готовность жить среди хаоса» и способность «процветать в условиях неустроенности»; клубной картой становится умение «позиционировать себя в переплетении возможностей, а не оставаться парализованным одной жизненной специальностью»; а визитной карточкой оказывается «согласие разрушить созданное собственными руками» ${ }^{15}$. Согласно Д. Н. Боровинской, модель человека как специалиста в сфере образования основана на компетентностном подходе [20].

Прежде всего, авторы полагают, что его образ будет формироваться из характеристик, свойственных работнику «общества знания», главной характеристикой которого будет умение работать с информацией, производить новое знание.

Его сущностными профессиональными чертами станут компетентность, конкурентоспособность, к ним добавятся такие личностные характеристики, как коммуникабельность, предприимчивость, гибкость и креативность мышления, способность к творчеству, восприимчивость и стремление к инновациям, лидерские качества, способность идти на риск, стрессоустойчивость, адаптивность, открытость (согласно экономической, социологической, комплексной, креативной, социально-

\footnotetext{
${ }^{15}$ Бауман 3. Индивидуализированное общество. - М.: Логос, 2005. - 390 с.

${ }^{16}$ Гусаковский М. А. Современный дискурс воспитания в университете: смена правил игры // «Забота о себе» как образовательная практика современного
}

культурной моделям человека [20]). Эти характеристики будут востребованы для возможности самостоятельного порождения знания. «Выпускник любой профессии в мире конкуренции сможет стать успешным лишь в случае овладения методологией порождения знания» [25, с. 509]. Если выпускник «классического университета» должен был овладеть квалификацией и иметь при этом широкий «кругозор», то выпускник современного университета в условиях рыночной конкуренции должен будет владеть метаквалификацией ${ }^{16}$ : быть способным эффективно действовать как ученый, предприниматель, менеджер, инженер, делопроизводитель, программист, лингвист одновременно.

Следовательно, университет нового поколения будет порождать не только высококвалифицированного специалиста, владеющего методологической исследовательской культурой, как в классические времена, но и владеющего навыками предпринимательства, документоведения, владения языками, информационно-коммуникационными технологиями. Помимо профессиональных качеств университет будет формировать гуманитарно-духовное начало выпускника, его личностную идентичность, соответствующую своему времени, современному прагматичному миру [25-27].

\section{Заключение}

В основание западноевропейского классического антропологического проекта была заложена идея «восхождения» к единой форме, идеалу, образцу, норме, смыслу, истине (будь то Эйдос - Бог - Красота - Опыт -

классического университета: сборник статей и материалов международной научной конференции / отв. ред. Г. И. Петрова. - Томск: Изд-во Том. ун-та, 2018. - С. 3-12. 
Рацио - Воля), а образование рассматривалось как способ «возведения» к готовой форме. Важное методологическое значение в этом контексте приобретает античная духовная практика «заботы о себе», где значимую роль играет наставник.

Современный антропологический проект отличен от классического. В эпоху, характеризующуюся неопределенностью, на смену классическому субстанционалистскому подходу приходит десубстанционализм, согласно которому нет никаких готовых форм, единых истин, смыслов и идеалов. Образование в новом антропологическом проекте, изложенном Ж. Лаканом, М. Фуко, Р. Бартом, Ж. Делезом, М. Хайдеггером, исходит из отсутствия у человека определенной сущности, и эксплицирует идею самости, свободы и ответственности за собственный выбор, ценностные ориентиры и предпочтения. Как осуществлять педагогический процесс, если педагог больше «...не вводит юношу в мир абсолютной истины, но знакомит его с гетерогенностью, каждый раз предлагающей свои новые грани и контексты истин? Он предлагает ему самому определиться в этой гетерогенности. Задача образования - не указать на истину, но научить узнать ее в открывшемся плюрализме и самостоятельно выбрать ее из тех вариантов и альтернатив, что предлагает современность. Человек в таком мире сам обязан уметь выбирать собственные стратегии развития, “создавать самому себя". Основным антропологическим ориентиром образования становится стратегия самоопределения. Антропологическая ситуация времени состоит в поисках новой идентичности, которые осуществляются в рамках этой стратегии» [19, с. 106-107]. В новом антропологическом проекте античная практика «заботы о себе» приобретает новую коннотацию как технику формирования себя.

Таким образом, социокультурные изменения, произошедшие на рубеже XX-XXI веков, привели к трансформации понимания смысла и назначения образования, его новой концептуализации, а также к поиску нового антропологического проекта, соответствующего своему времени, который видится теперь в стратегии самоопределения, саморазвития, самосозидания обучающегося.

\section{СПИСОК ЛИТЕРАТУРЫ}

1. Бауман 3. Текучая современность: монография / пер. с англ. С. А. Комарова. - М.: Питер, 2008. -238 c. URL: https://elibrary.ru/item.asp?id=19650047

2. Барнетт P. Осмысление университета // Alma Mater (Вестник высшей школы). - 2008. № 6. - C. 46-57. URL: https://elibrary.ru/item.asp?id=11582781

3. Бек У. Общество риска: На пути к другому модерну: монография. - М.: Прогресс-Традиция, 2000. -384 c. URL: https://elibrary.ru/item.asp?id=20241833

4. Ardashkin I. B. Philosophy of Education as a Social Development Factor: World Trends and Prospects for Russia // Procedia - Social and Behavioral Sciences. - 2015. - Vol. 166. - P. 277286. DOI: https://doi.org/10.1016/j.sbspro.2014.12.524

5. Rogobete S. E. The Self, Technology and the Order of Things: In Dialogue with Heidegger, Ellul, Foucault and Taylor // Procedia - Social and Behavioral Sciences. - 2015. - Vol. 183. - P. 122128. DOI: https://doi.org/10.1016/j.sbspro.2015.04.854

6. Cristian I. Foucault's Idea of Philosophy as "Care of the Self”: Critical Assessment and Conflicting Metaphilosophical Views // Procedia - Social and Behavioral Sciences. - 2013. - Vol. 71. - P. 7685. DOI: https://doi.org/10.1016/j.sbspro.2013.01.011 
7. Hrbackova K., Suchankova E. Self-Determination Approach to Understanding of Motivation in Students of Helping Professions // Procedia - Social and Behavioral Sciences. - 2016. - Vol. 217. P. 688-696. DOI: https://doi.org/10.1016/j.sbspro.2016.02.120

8. Gonzalez-Cutre D., Sicilia A., Sierra A. C., Ferriz R., Hagger M. S. Understanding the need for novelty from the perspective of self-determination theory // Personality and Individual Differences. - 2016. - Vol. 102. - P. 159-169. DOI: https://doi.org/10.1016/j.paid.2016.06.036

9. Ryan R. M., Deci E. L. Self-determination theory: Basic psychological needs in motivation, development, and wellness. - New York: The Guilford Press, 2017. - 756 p. URL: https://searchworks.stanford.edu/view/11966826

10. Deci E. L., Olafsen A. H., Ryan R. M. Self-Determination Theory in Work Organizations: The State of a Science // Annual Review of Organizational Psychology and Organizational Behavior. - 2017. - Vol. 4. - P. 19-43. DOI: https://doi.org/10.1146/annurev-orgpsych-032516113108

11. Аванесов С. С. Самореализация и самосозидание // Вестник Томского государственного университета. Философия. Социология. Политология. - 2009. - № 2 (6). - С. 133-135. URL: https://elibrary.ru/item.asp?id=11968237

12. Завьялов Б. М. Антропологический проект Платона в современной практике философского образования // Человек. Культура. Образование. - 2013. - № 1. - С. 12. URL: https://elibrary.ru/item.asp?id=21116265

13. Сапогова Е. Е. «Забота о себе»: автопостроение жизни как смысловой системы // Вестник гуманитарного образования. - 2015. - № 3. - C. 49-66. URL: https://elibrary.ru/item.asp?id=26552350

14. Розин В. М. Концепция «заботы о себе»: философская, научная, художественная и авторская версии // Культура и искусство. - 2017. - № 7. - С. 50-56. URL: https://elibrary.ru/item.asp?id=29809825

15. Красиков В. И. Рефлексирующее воспоминание в формировании «Я» // Вестник Томского государственного университета. Философия. Социология. Политология. - 2017. - № 39. C. 22-29. DOI: https://elibrary.ru/item.asp?id=30715382

16. Петрова Г. И. «Забота о себе»: технология или антропология? // Вестник Томского государственного университета. Философия. Социология. Политология. - 2009. - № 2. C. 136-143. URL: https://elibrary.ru/item.asp?id=11968238

17. Вишневский Ю. Р., Вишневский С. Ю. Идеи М. Фуко об образовании как социальном институте // Вестник Сургутского государственного педагогического университета. - 2015. № 2 (35). - C. 25-32. URL: https://elibrary.ru/item.asp?id=24380799

18. Petrova G. I., Gural A. K., Brylina I. V., Kornienko A. A., Stupnikova O. B. "The Care of the Self” Practice in a Contemporary Culture // The European Proceedings of Social \& Behavioural Sciences (EpSBS). $\quad-\quad 2016 . \quad-\quad$ Vol. XIX. $\quad-\quad$ P. 666-673. DOI: http://dx.doi.org/10.15405/epsbs.2017.01.88

19. Ямпольская Л. И. Концептуализация классической «Идеи университета» в неклассическом варианте: монография. - Томск: СТT, 2014. - 228 с. URL: https://elibrary.ru/item.asp?id=22947175

20. Боровинская Д. Н. Креативно-информационная модель человека: философский анализ социальных взаимосвязей: монография. - Тюмень: Изд-во Тюменского государственного университета, 2010. - 125 c. URL: https://elibrary.ru/item.asp?id=19669521

21. Petrova G., Smokotin V., Brylina I., Kornienko Al., Kornienko An., Nikitina Y., Kachalov N. A Comparative Analysis of Classical and Postmodern Views on the Idea of a University // 
Procedia - Social and Behavioral Sciences. - 2015. - Vol. 206. - P. 469-473. DOI: http://dx.doi.org/10.1016/j.sbspro.2015.10.085

22. Kazarina L., Itsenko I. Research Competencies Condition Assessment of Pupils from Humanitarian-oriented Classes of Comprehensive School // Procedia - Social and Behavioral Sciences. - 2015. - Vol. 206. - P. 342-347. DOI: https://doi.org/10.1016/j.sbspro.2015.10.062

23. Karpov A. O. Dissonance tolerance as a new principle of the cross-cultural sustainability // Procedia - Social and Behavioral Sciences. - 2017. - Vol. 237. - P. 723-730. DOI: https://doi.org/10.1016/j.sbspro.2017.02.113

24. Боровинская Д. Н. Креативное мышление: основные направления исследования // Вестник Томского государственного университета. Философия. Социология. Политология. - 2017. № 40. - C. 22-31. URL: https://elibrary.ru/item.asp?id=30778979

25. Petrova G. I., Brylina I. V., Kulizhskaya E. G., Bogoryad N. V. Corporate culture of contemporary research university in search of complementarity of humanitarian and commercial principles in education (Russian context) // Procedia - Social and Behavioral Sciences. - 2015. Vol. 166. - P. 505-510. DOI: http://dx.doi.org/10.1016/j.sbspro.2014.12.562

26. Petrova G., Gural S., Brylina I., Kornienko Al., Kornienko An., Nikitina U., Kachalov N. Humanitarian Meaning of University Professional Education // Procedia - Social and Behavioral Sciences. - 2015. - Vol. 206. - P. 455-458. DOI: https://doi.org/10.1016/j.sbspro.2015.10.082

27. Anikina E., Ivankina L., Tumanova I. Human Well-being and Educational Investment Efficiency // Procedia - Social and Behavioral Sciences. - 2015. - Vol. 166. - P. 48-52. DOI: http://dx.doi.org/10.1016/j.sbspro.2014.12.481 
DOI: $10.15293 / 2226-3365.1805 .09$

Irina Vladimirovna Brylina,

Candidate of Philosophical Sciences, Associate Professor,

Social Sciences and Humanities Department,

National Research Tomsk Polytechnic University, Tomsk, Russian Federation.

ORCID ID: http://orcid.org/0000-0001-8947-9916

E-mail: ibrylina@yandex.ru

\section{Formation of new anthropological project of the modern education in the context of non-classical philosophy}

\section{Abstract}

Introduction. The author investigates the problem of rethinking the Western European classical heritage by the philosophy of education. The purpose of the research is to reveal the potential of nonclassical philosophy to the formation of a new anthropological project of modern education.

Materials and Methods. The author uses methods of analysis and synthesis studying the genesis and evolution of education in different historical epochs: from Antiquity to the present day. The method of comparative analysis is applied to comparing and revealing the differences between anthropological projects of classical and nonclassical philosophy as ways of connecting man and education. The categories of Plato's 'taking care of the self' and M. Foucault's 'techniques of the self' are explicated.

Results. The connection between human evolution and transformation of education is clarified. The author analyses the changes of anthropological projects in the context of education evolution from Antiquity to the present day and compares Plato and M. Foucault's practices of 'taking care of the self". The potential of nonclassical philosophy to form a new anthropological project of modern education is revealed.

Conclusions. It is concluded that the new anthropological project of education is different from classical projects which were based on the "ascent" to a single form, to the ideal, the model, the norm, the meaning, and the truth (Eidos - God - Beauty - Experience - Racio - Will). The main anthropological idea of modern university education is the strategy of self-determination, self-development and selfactualization of a learner.

Keywords

Human Evolution; Philosophy of education; Evolution of education; Transformation of education; New anthropological project; Self-determination; Self-actualization.

\section{Acknowledgements}

This research was supported by Tomsk Polytechnic University.

\section{REFERENCES}

1. Bauman Z. Liquid Modernity. Cambridge, Polity Press Publ., 2006, 228 p. URL: https://elibrary.ru/item.asp?id=19650047

2. Barnett R. Understanding the university. Alma Mater, 2008, no. 6, pp. 46-57. (In Russian) URL: https://elibrary.ru/item.asp?id=11582781

3. Beck U. Risk Society: Towards Another Modernity. Monograph. Moscow, Progress-Tradition Publ., 2000, 384 p. (In Russian) URL: https://elibrary.ru/item.asp?id=20241833 
4. Ardashkin I. B. Philosophy of education as a social development factor: World trends and prospects for Russia. Procedia - Social and Behavioral Sciences, 2015, vol. 166, pp. 277-286. DOI: https://doi.org/10.1016/j.sbspro.2014.12.524

5. Rogobete S. E. The self, technology and the order of things: In Dialogue with Heidegger, Ellul, Foucault and Taylor. Procedia - Social and Behavioral Sciences, 2015, vol. 183, pp. 122-128. DOI: https://doi.org/10.1016/j.sbspro.2015.04.854

6. Cristian I. Foucault's idea of philosophy as "care of the self": Critical assessment and conflicting metaphilosophical views. Procedia - Social and Behavioral Sciences, 2013, vol. 71, pp. 76-85. DOI: https://doi.org/10.1016/j.sbspro.2013.01.011

7. Hrbackova K., Suchankova E. Self-determination approach to understanding of motivation in students of helping professions. Procedia - Social and Behavioral Sciences, 2016, vol. 217, pp. 688-696. DOI: https://doi.org/10.1016/j.sbspro.2016.02.120

8. Gonzalez-Cutre D., Sicilia A., Sierra A. C., Ferriz R., Hagger M. S. Understanding the need for novelty from the perspective of self-determination theory. Personality and Individual Differences, 2016, vol. 102, pp. 159-169. DOI: https://doi.org/10.1016/j.paid.2016.06.036

9. Ryan R. M., Deci E. L. Self-determination theory: Basic psychological needs in motivation, development, and wellness. New York, The Guilford Press Publ., 2017, 756 p. URL: https://searchworks.stanford.edu/view/11966826

10. Deci E. L., Olafsen A. H., Ryan R. M. Self-determination theory in work organizations: The state of a science. Annual Review of Organizational Psychology and Organizational Behavior, 2017, vol. 4, pp. 19-43. DOI: https://doi.org/10.1146/annurev-orgpsych-032516-113108

11. Avanesov S. S. Self-realization and self-creation. Tomsk State University Journal of Philosophy, Sociology and Political Science, 2009, no. 2, pp. 133-135. (In Russian) URL: https://elibrary.ru/item.asp?id=11968237

12. Zavyalov B. M. Anthropological project of Plato in the modern practice of philosophical education. Human. Culture. Education, 2013, no. 1, pp. 12. (In Russian) URL: https://elibrary.ru/item.asp?id=21116265

13. Sapogova E. E. "Care about myself”: Autobuilding life as a semantic system. Herald of Humanitarian Education, 2015, no. 3, pp. 49-66. (In Russian) URL: https://elibrary.ru/item.asp?id=26552350

14. Rozin V. M. The concept of "taking care of yourself": philosophical, scientific, artistic and author's versions. Culture and Art, 2017, no. 7, pp. 50-56. (In Russian) URL: https://elibrary.ru/item.asp?id=29809825

15. Krasikov V. I. Reflective remembrance in the formation of self. Tomsk State University Journal of Philosophy, Sociology and Political Science, 2017, no. 39, pp. 22-29. (In Russian) URL: https://elibrary.ru/item.asp?id=30715382

16. Petrova G. I. "Take care of myself" is technology or anthropology. Tomsk State University Journal of Philosophy, Sociology and Political Science, 2009, no. 2, pp. 136-143. (In Russian) URL: https://elibrary.ru/item.asp?id=11968238

17. Vishnevsky Yu. R., Vishnevsky S. Yu. The ideas of M. Foucault on education as a social institute. Surgut State Pedagogical University Bulletin, 2015, no. 2, pp. 25-32. (In Russian) URL: https://elibrary.ru/item.asp?id=24380799

18. Petrova G. I., Gural A. K., Brylina I. V., Kornienko A. A., Stupnikova O. B. "The care of the self” practice in a contemporary culture. European Proceedings of Social \& Behavioural Sciences (EpSBS), 2016, vol. XIX, pp. 666-673. DOI: http://dx.doi.org/10.15405/epsbs.2017.01.88 
19. Yampolskaya L. I. Conceptualizing of classical "idea of the university" in nonclassical variant. Monograph. Tomsk, STT Publ., 2014, 228 p. (In Russian) URL: https://elibrary.ru/item.asp?id=22947175

20. Borovinskaya D. N. Creative-informational model of man: a philosophical analysis of social interrelations. Monograph. Tyumen, Tyumen State University Publ., 2010, 125 p. (In Russian) URL: https://elibrary.ru/item.asp?id=19669521

21. Petrova G., Smokotin V., Brylina I., Kornienko Al., Kornienko An., Nikitina Y., Kachalov N. A comparative analysis of classical and postmodern views on the idea of a university. Procedia - Social and Behavioral Sciences, 2015, vol. 206, pp. 469-473. DOI: http://dx.doi.org/10.1016/j.sbspro.2015.10.085

22. Kazarina L., Itsenko I. Research competencies condition assessment of pupils from humanitarianoriented classes of comprehensive school. Procedia - Social and Behavioral Sciences, 2015, vol. 206, pp. 342-347. DOI: https://doi.org/10.1016/j.sbspro.2015.10.062

23. Karpov A. O. Dissonance tolerance as a new principle of the cross-cultural sustainability. Procedia - Social and Behavioral Sciences, 2017, vol. 237, pp. 723-730. DOI: http://dx.doi.org/10.1016/j.sbspro.2017.02.113

24. Borovinskaya D. N. Creative thinking: the main directions of research. Tomsk State University Journal of Philosophy, Sociology and Political Science, 2017, no. 40, pp. 22-31. (In Russian) URL: https://elibrary.ru/item.asp?id=30778979

25. Petrova G. I., Brylina I. V., Kulizhskaya E. G., Bogoryad N. V. Corporate culture of contemporary research university in search of complementarity of humanitarian and commercial principles in education (Russian context). Procedia - Social and Behavioral Sciences, 2015, vol. 166, pp. 505510. DOI: http://dx.doi.org/10.1016/j.sbspro.2014.12.562

26. Petrova G., Gural S., Brylina I., Kornienko Al., Kornienko An., Nikitina U., Kachalov N. Humanitarian meaning of university professional education. Procedia - Social and Behavioral Sciences, 2015, vol. 206, pp. 455-458. DOI: http://dx.doi.org/10.1016/j.sbspro.2015.10.082

27. Anikina E., Ivankina L., Tumanova I. Human well-being and educational investment efficiency. Procedia - Social and Behavioral Sciences, 2015, vol. 166, pp. 48-52. DOI: http://dx.doi.org/10.1016/j.sbspro.2014.12.481 